\title{
Fahud-feltet \\ - et gigantisk oliefelt i Oman
}

\section{Af geolog Nick Svendsen}

Efterforskningsaktiviteter støder ofte på overraskelser, og den første boring påviser ikke altid olie. Her er historien om, hvorledes det første olieselskab opgav, og det næste fandt næsten 6 mia. tønder olie halvanden kilometer fra den første boring.

Fahud-feltet ligger i Nordoman ca. $250 \mathrm{~km}$ fra hovedstaden, Muscat (figuren øverst på næste side). Det blev fundet ved boringen Fahud North-2 i 1964, men som navnet antyder, var det ikke den første boring. Fahud-1 blev boret i 1956, men viste sig at være en tør boring.

Det er snart 50 år siden, og da historien om Fahud rummer nogle interessante aspekter vedrørende olieefterforskning, skal historien gengives her.

\section{Den tidlige efterforskningsfase}

Kører man af hovedvejen fra Muscat ind igennem bjergene og ud i ørken, oplever man først Omans imponerende bjerge kaldet Jebel Akhdar, herefter "the foothills" af bjergene opkaldt efter Duru-stammen, der lever i området, Hamrat Duru. Dernæst flader landet ud. Med mellemrum rejser en serie af bjerge sig op ad sandet, først Jebel Madmar, Jebel Salakh, Natih-Antiklinalen og endelig Jebel Fahud (figuren øverst næste side). Alle fire er antiklinaler foldet op $i$ forbindelse med dannelsen af Omans bjerge. Jebel Fahud og Natih er i dag oliefelter.

Jebel Fahud-antiklinalen har aksen orienteret nordvest-sydøst (figuren nederst næste side). Siderne af antiklinalen består af Umm Er Radhuma-kalksten, og centralt i antiklinalen findes den underliggende Fiqaskifer. Denne struktur blev erkendt så tidligt som i 1948 ved fly-rekognoscering. Efterfølgende i 1954 blev der foretaget geofysiske målinger (gravimetri og magnetiske målinger) og lavet en overfladegeologisk kortlægning. To år senere var man så klar til at bore. Boretårnet blev bragt ind med fly, idet vejene i bjergene ikke eksisterede dengang. Boringens primære mål var reservoirerne i Natih- og Shuaiba-Formationerne. Boringen sluttede i palæozoisk salt og fandt Natih-Formationen kun tyndt udviklet, men dog med spor af olie. Efterforskningen blev opgivet.

I 1960 overtog Shell operatørskabet, og i

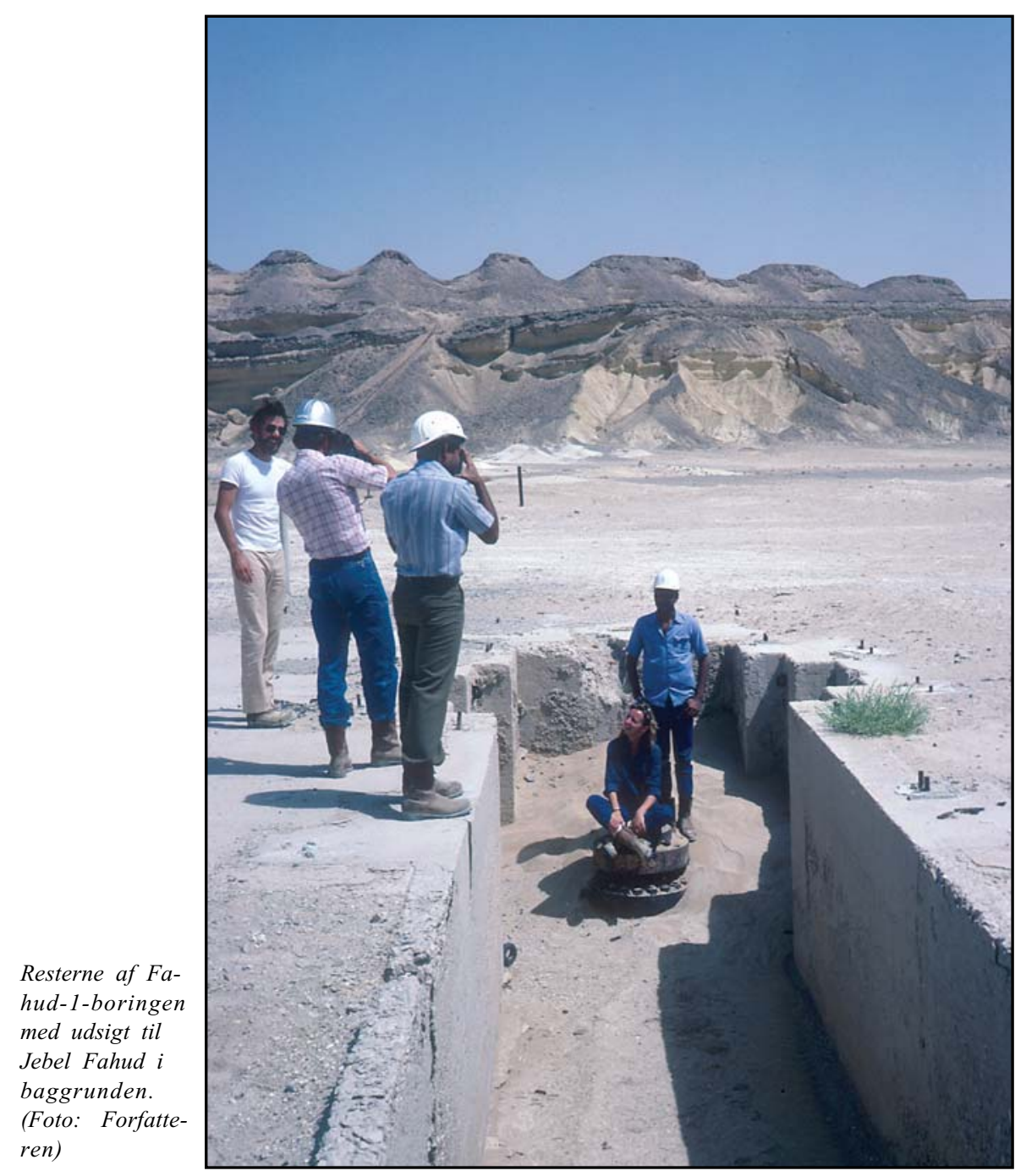

perioden 1962 til 1963 blev der fundet olie i Yibal- og Natih-felterne i henholdsvis Shuaiba- og Natih-Formationerne. Det gav fornyet interesse for Fahud. Seismiske målemetoder var siden halvtredserne blevet stærkt udviklede, og ny seismik over

Fahud-strukturen antydede, at Fahud-1 var boret på et forkert sted. Fahud North-2 blev boret i 1964 i en afstand af $1,5 \mathrm{~km}$ fra den forste boring, og her blev Natih-Formationen fundet - ca. $500 \mathrm{~m}$ tyk og fyldt med olie (figurerne på næste side).

For at forklare denne situation må vi se nærmere på den geologiske opbygning af Fahud-feltet.

\section{Reservoiret}

Som nævnt fandtes der olie i Natih-Formationen i Fahud-feltet. Da dette reservoir er blevet beskrevet tidligere i dette tidsskrift (4/03), skal jeg ikke nøjere beskrive det blot nævne, at det minder meget om reservoirerne i Natih-feltet, og at dette reservoir er $500 \mathrm{~m}$ tyk (figuren øverst på næste opslag).

\section{Strukturen}

Som nævnt anborede Fahud-1 boringen palæozoisk salt af Ara-Formationen. Det antyder, at Fahud-strukturen kunne være induceret af en underliggende saltstruktur, og at saltbevægelser er en del af forklaringen på strukturens tilstedeværelse. Boredata understøtter, at der under aflejringen af Natih-Formationen og i tiden før (dvs. før Tertiær) var strukturelle bevægelser. Efter Natih-Formationens aflejring blev landet hævet og udsat for et stræk i forbindelse med dannelsen af forlandsbassinet foran de store overskydninger i Omans bjerge. Det betød bevægelser i allerede eksisterende forkastninger både vertikalt (normalforkastninger) og sideværts (strike slip-forkastninger). Inden havet vendte tilbage, var strukturen blottet, hvad der resulterede i erosion og karstdannelse i kalken (de fem sidste figurer i artiklen).

Herefter aflejredes Fiqa-skifren, og kalken blev dækket. Der var endnu bevægelse i strukturen formodentligt relateret til salt- 


\section{Nordoman, olie- og gasfelter}

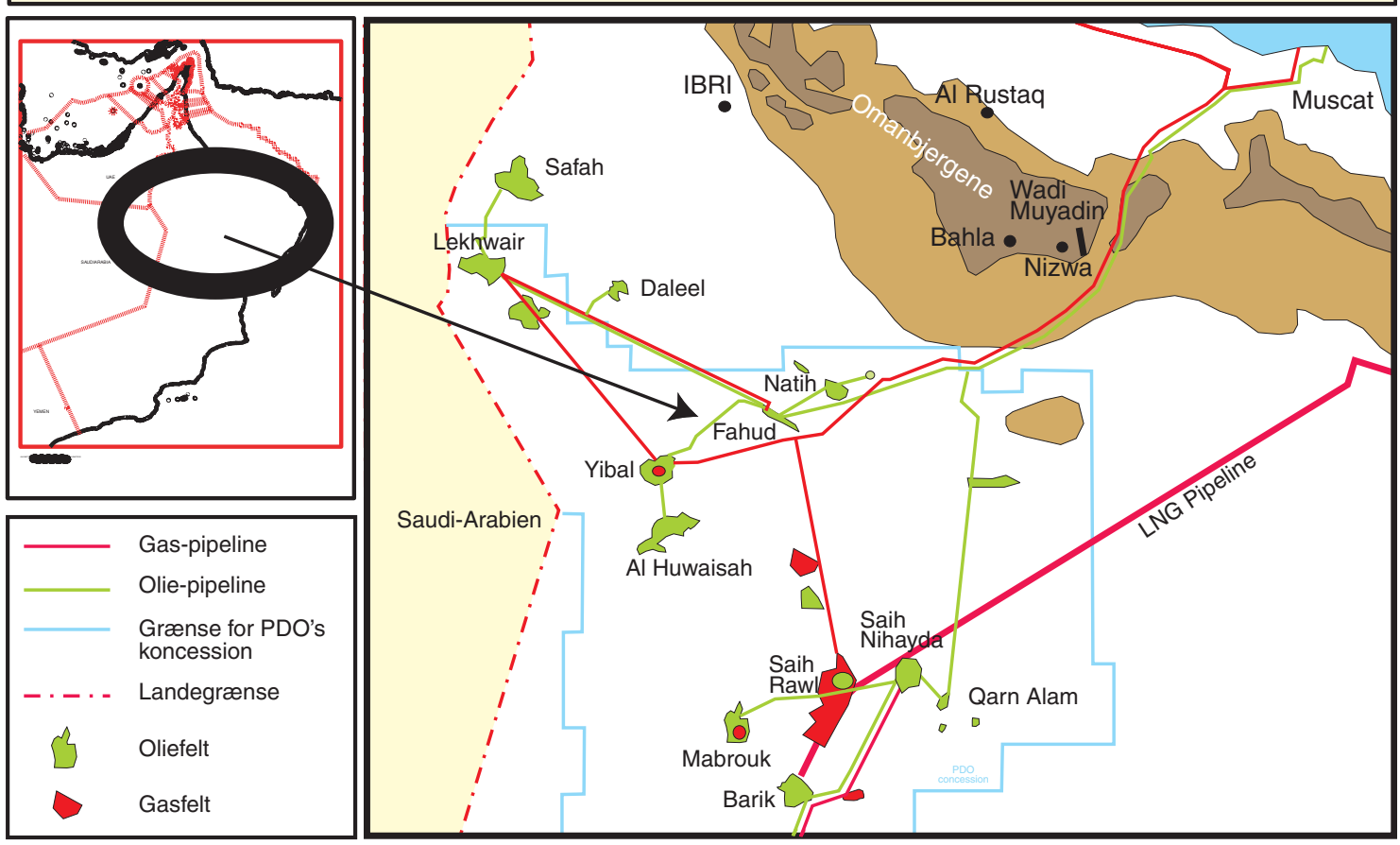

bevægelser. Herefter aflejredes Hadramautog Fars-Gruppernes kalksten og evaporitter. Men allerede i sen Tertiær i forbindelse med forskydningstektonikken i bjergene presses området sammen. Fahudforkastningsblokken har et relief på ca. 600 $\mathrm{m}$ og fungerer som en fast blok. Den mere bløde Fiqa-skifer presses mod kalken og foldes. Herved fremstår Fahud-strukturen som en antiklinal ved overfladen, og som en hældende forkastningsblok i dybden.

Her har vi så forklaringen på, at Fahud-1 var tør. Denne boring blev boret nær toppen af overfladestrukturen (figuren til højre), men ramte Natih-Formationen i den store forkastning og så uheldigt, at det meste af formationen var vækforkastet (figuren øverst på næste side).

\section{Udviklingen af feltet}

Da toppen af reservoiret ligger i ca. $600 \mathrm{~m}$ 's dybde under overfladen (figuren nederst på næste side), er en produktionsbrønd sjældent mere end $1.100 \mathrm{~m}$ dyb. Det tager omkring en uge fra boringen bliver påbegyndt, til den er boret og klargjort til produktion. Så siden feltet blev fundet, er der konstant blevet boret i Fahud-feltet. Produktionsanlægget (midterste figur næste side) blev installeret i 1966, således at produktionen kunne starte fra de første 11 produktionsbrønde i juli 1967.

I 1969 toppede produktionen med $34.800 \mathrm{~m}^{3}$ olie om dagen (220.000 tønder olie om dagen) fra 64 boringer. Produktionen er nu faldet til ca. $9.000 \mathrm{~m}^{3}$ per dag (57.000 tønder olie om dagen). Der er efterhånden boret over 300 boringer, hvoraf ca. 50 er horisontale. De horisontale boringer yder $70 \%$ af produktionen resten kommer fra 50-60 konventionelle vertikale boringer.
Feltet rummer 1.000 millioner $\mathrm{m}^{3}$ olie (ca. 6.000 millioner tønder olie), hvoraf man regner med at kunne producere $20 \%$. Feltet har indtil nu produceret 145 million $\mathrm{m}^{3}$ olie (ca. 900 millioner tønder olie).

De første boringer producerede omkring $1,000 \mathrm{~m}^{3}$ per dag, men i dag producerer en vertikal brønd $50 \mathrm{~m}^{3}$ per dag og en horisontal brønd ca. $130 \mathrm{~m}^{3}$ per dag.

Man observerede tidligt en nedgang i reservoirtrykket og forsøgte så at opret- holde trykket ved gasinjektion. Det resulterede $\mathrm{i}$, at gas-oliekontakten rykkede nedad til niveauet for produktionsbrøndene med det resultat, at de producerede øgede mængder gas. Man stoppede derfor gasinjektionen i 1967 og påbegyndte i stedet vandinjektion. I dag bruger man en kombination af gas- og vandinjektion dog i forskellige dele af feltet. Det skal nævnes, at overskudsgassen bliver eksporteret ud til kysten til brug i kraftværker.
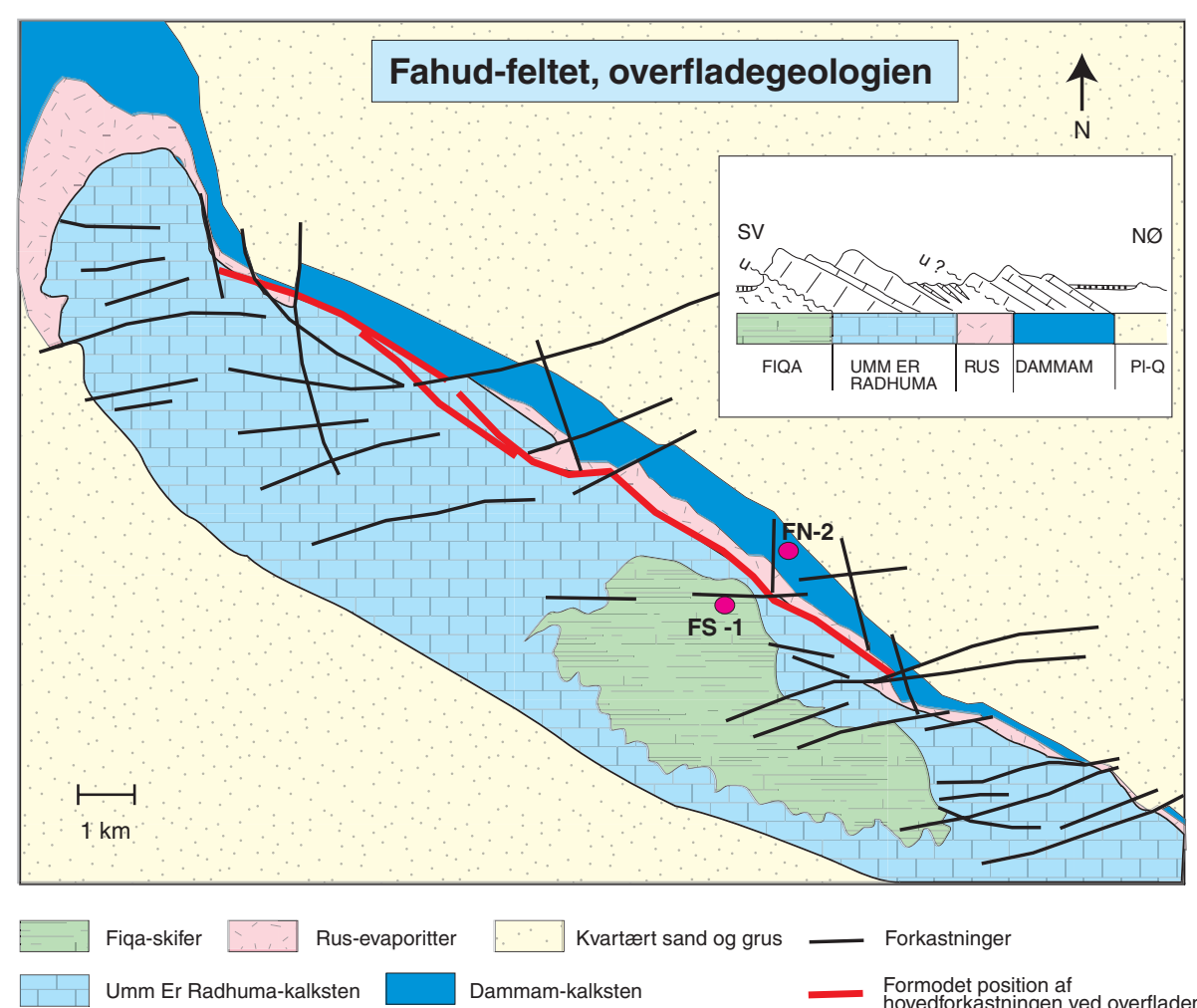

Overfladekortet viser, at Fahud-feltet fremstår som en antiklinal. Positionen af de to forste boringer er vist med røde pletter. Som man kan se, er Fahud 1 (FS-1) boret centralt på strukturen. (Grafik: Forfatteren) 
Alle reservoirerne har en fælles olievandkontakt på grund af opsprækning. Da der samtidig er en gaskappe, som siden produktionens start er ekspanderet, bores Natih A-produktionsboringerne længst mod nordøst, dernæst kommer en række med Natih C- og D-boringer og til sidst Natih E samt F og G. Da Shuaiba-Formationen også er olieførende i Fahud-feltet, findes der en række Shuaba-boringer yderst mod sydvest.

\section{Det er ikke altid let}

En vertikal produktionsboring i Fahud-feltet tager en uge at bore. Som regel er der ingen boreproblemer, men $\mathrm{fx}$. Fiqa-skifren kan drille, idet den har det med at svulme op, når den kommer i kontakt med vand. Har man ikke nået at sætte forerør over Fiqa-skifren, kan det være svært at kontrollere den, og hullet kan falde sammen, hvorved borestrengen sætter sig fast. Umm Er Radhuma-kalkstenen er opsprækket, og man har ofte store tab af boremudder i denne kalksten.

"Blow out" (dvs. ukontrolleret tilstrømning af olie og/eller gas til boringen) hører til sjældenhederne, men $i$ en af de tidligere boringer (man var i gang med at tage en kerne $i$ toppen af Natih-Formationen) faldt bore-

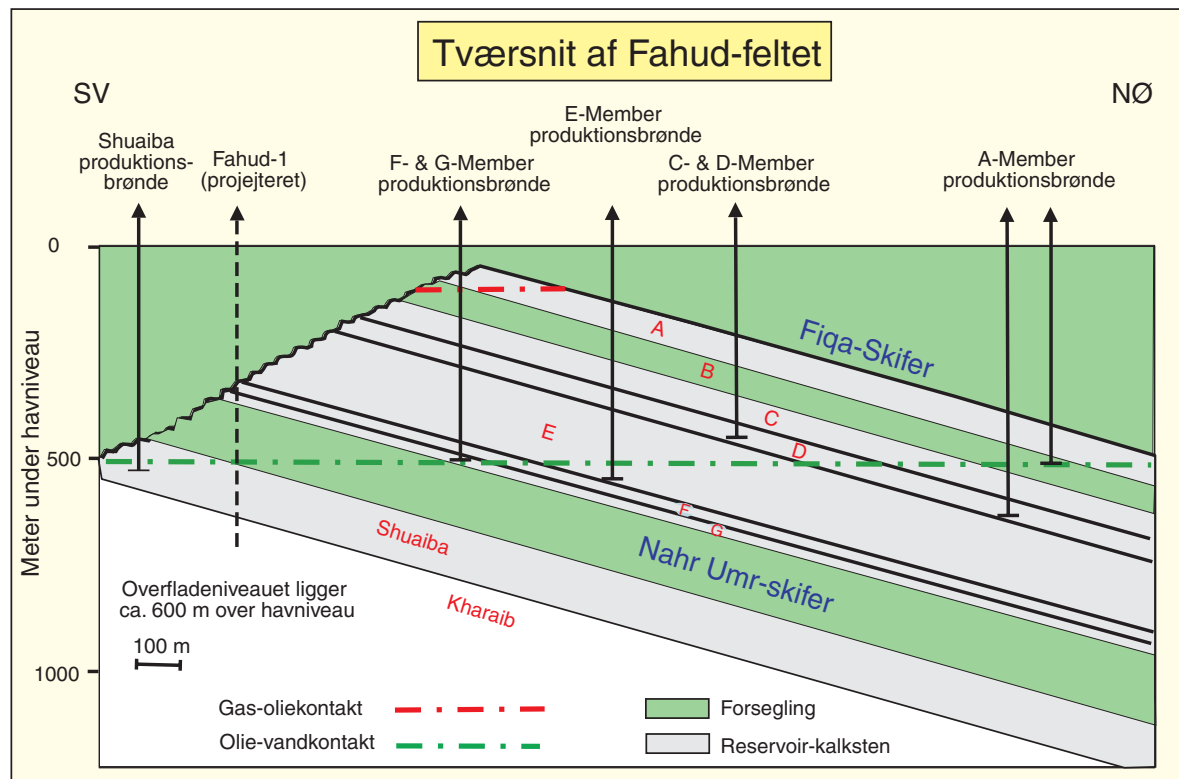

Tvarsnit af Fahud-feltet der viser, at det ikke er en antiklinal på Natih-reservoirniveau. Fahud1 er projiceret ind på figuren, og man kan se, hvorfor den var tør. Boringen snittede lige oliezonen $i$ Natih-E-reservoiret. (Grafik: Forfatteren)

strengen pludselig ned $i$ et hul med en dybde på $1,2 \mathrm{~m}$. Boremudderet forsvandt ned i hullet, og da boringen ligger på toppen af strukturen, fik man et "gas blow out". Man fik dog hurtigt kontrol over gasudslippet, og bo-

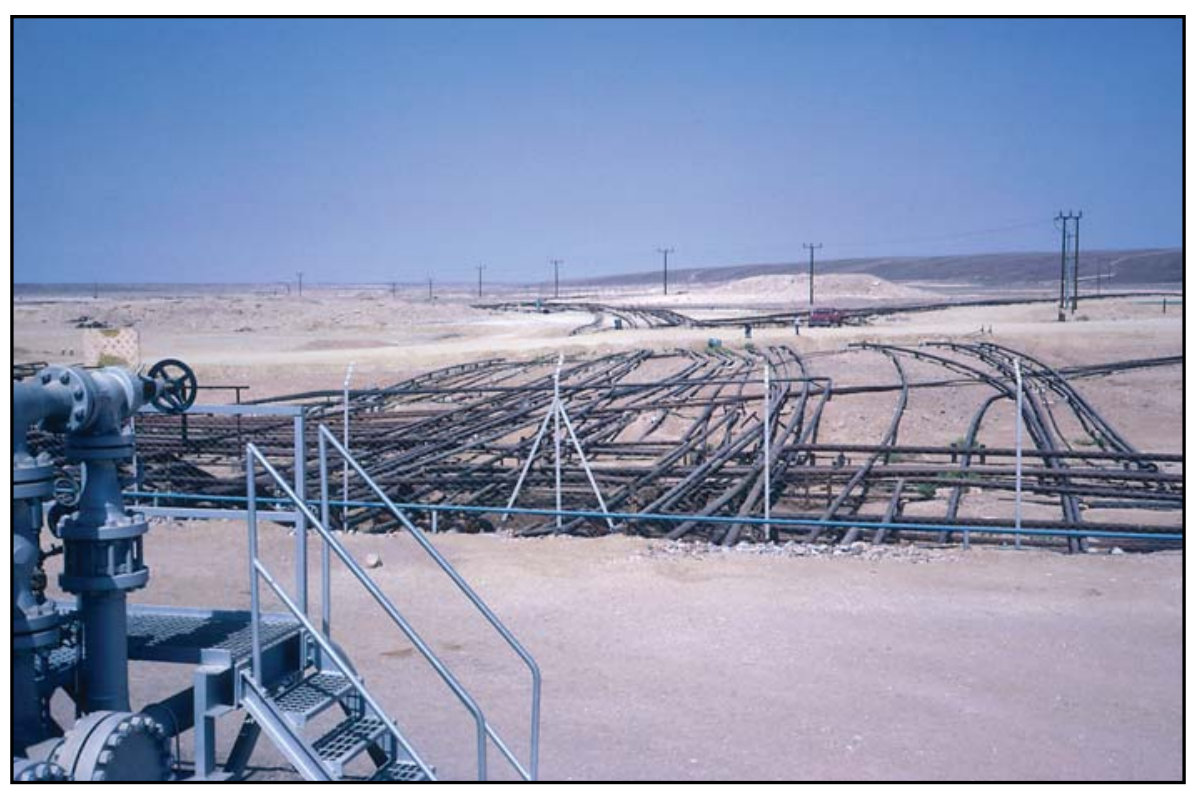

ringen blev fyldt med cement og opgivet.

Som nævnt er den sydvestlige flanke en forkastningsflade, som er blevet eroderet. Dvs. man møder mange overraskelser i form af erosionskanaler eller "slumps" med store væltede blokke således, at det lag, man håber på at finde, ikke er der, eller yngre lag forekommer dybere end oprindeligt antaget.

Det kan resultere i en tør boring midt i et stort oliefelt. Tilbage i 1980'erne fandtes der kun 4 seismiske linier igennem feltet. Topografien gjorde, at det var meget besværligt at indsamle seismiske data. Ny teknik har ændret dette, og der findes en 3D-seismisk survey over feltet, og flanken er nu meget bedre defineret.

\section{En Kæmpe på retur}

Fahud-feltet er et gigantisk oliefelt, der er i sin sidste fase. Hvor længe olieproduktionen er rentabel, er svært at vide. Fahud-feltet er samtidigt center for Nordomans olie- og gasproduktion. Feltets faciliteter tjener derfor forskellige formål. Når olieproduktionen er slut, er gassen tilbage, som kan blæse nyt liv igiganten.

"Pipeline-spaghetti" på nordøstsiden af Fahud-feltet. (Foto: Forfatteren)

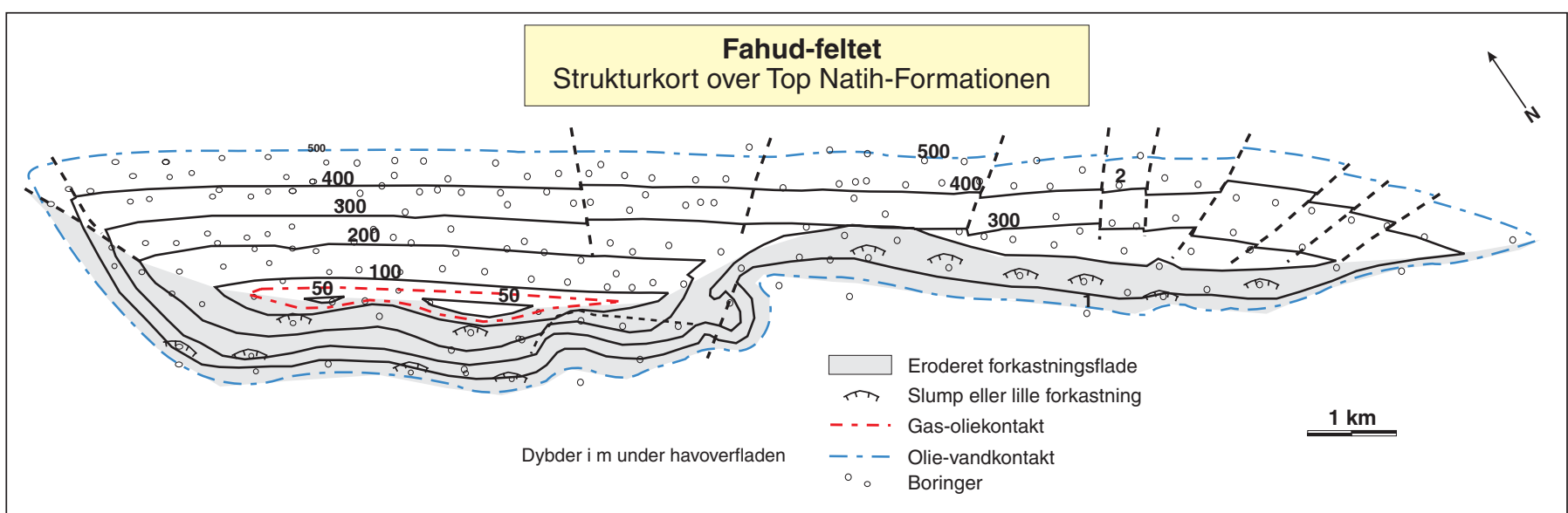

Strukturkortet fra toppen af Natih-Formationen er nasten udelukkende baseret på resultaterne af de mange boringer. Faktisk er der brugt 4 seismiske linier. I dag er det anderledes, hvor feltet er dakket af 3D-seismik. (Grafik: Forfatteren) 


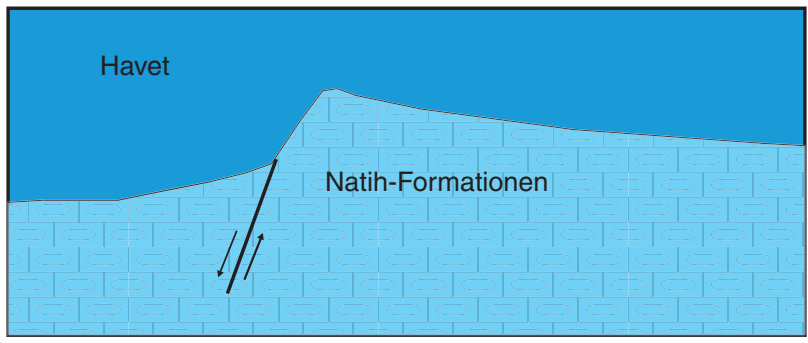

Øvre Kridt, Albien (100 mio. år)

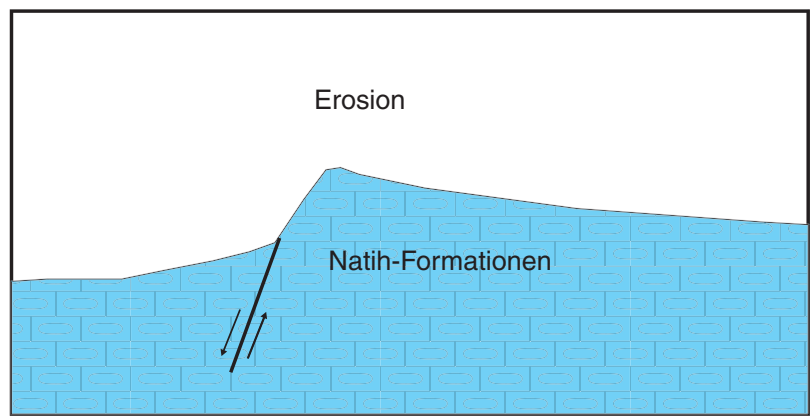

Øvre Kridt, Coniacien (92 mio. år)

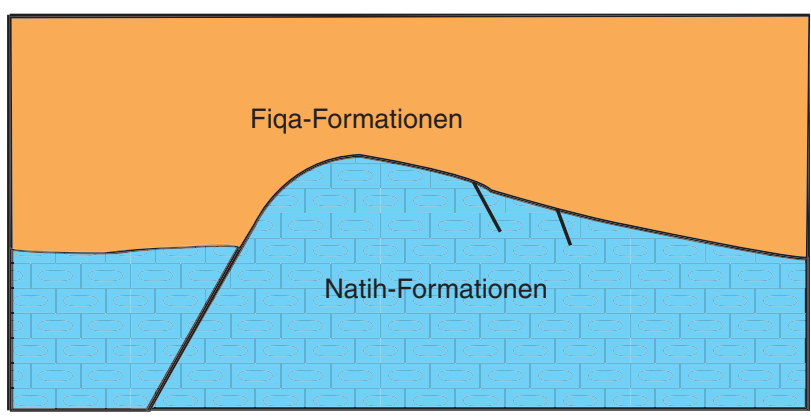

Øvre Kridt, Campanien (80 mio. år)

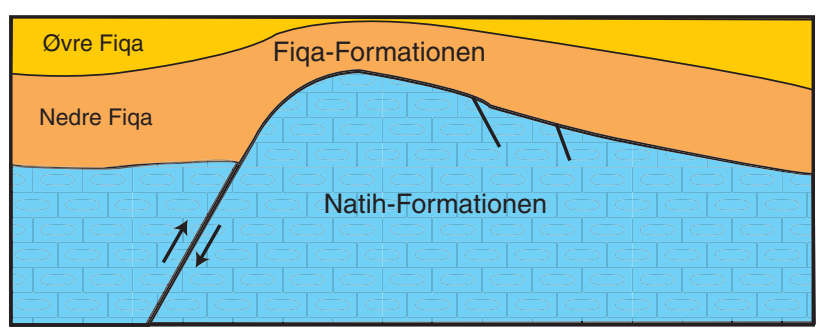

Øvre Kridt, Maastrichtien (65 mio. år)

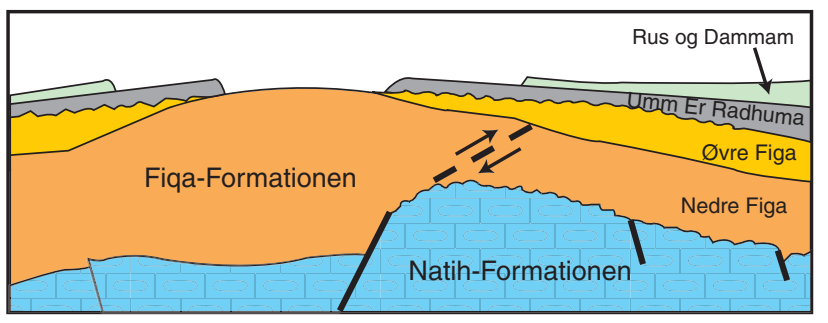

Efter aflejring af FarsFormationen sammenpressedess området $i$ løbet af Miocan. Natih-kalken reagerede som en fast blok mod den mere plastiske Fiqa-ler, som blev sammentrykket og formede den nutidige antiklinal.
3. Herefter aflejres FiqaFormationen. Man mener, at Fahud-strukturen havde et relief allerede på dette tidspunkt på ca. $600 \mathrm{~m}$. I FS-9 (boret sydvest for strukturen) er Fiqa-skifren ca. $1.000 \mathrm{~m}$ tyk, mens den på toppen af strukturen i FN-3 er ca. 400 $m$ tyk. gen af den øverste del af presning og erosion forekommer.
2. Situationen efter aflejrinmen for aflejringen af FiqaFormationen. Horizontale pression). Natih-formationen og udsat for karstdannelse. Erosionen er specielt udtalt på forkastningsfladen. giver anledning til nogen

Nutid

Farver og signaturer på de enkelte lag afspejler ikke lithologi, men Natih-lagene er overvejende kalksten med nogle markante lerlag. Fiqa består overvejende af ler og mergel, mens Umm Er Radhuma udgøres af kalksten. (Grafik: Forfatteren og UVH) 